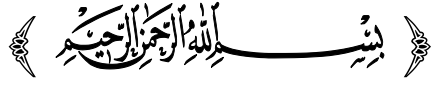

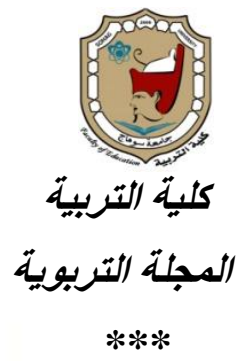

الثروق في السلوك التوكيدي بين المعتمدين وغير المئرية

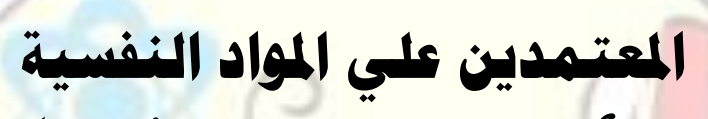

Differences in Assertiveness Between Psychoactive Substances

Dependents Patients and $\mathcal{N}$ on-dependents

\title{
إعداد
}

\section{أ. مصطفى إبراهيم محمد}

المعالج النفسي بمستشفى د.عادل صادق إنرائ مجمل للطب النفسى-القاهرة

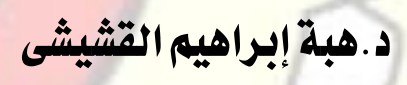

أستاذ علم النفس بكلية التربية جامعة الملك خالد

وأستاذ علم النفس بكلية الآداب جامعة المنيا 
ملخص:

يهرف البحث الحالي إلى الكثف عن الفروق بين المعتمدين وغير المعتمدين علي المواد النفسية في السلوك التوكيدي. وقد أُجريالبحث الحالي علي عينة قوامها ( . . . ذبكر)، . . . من المعتمدين علي المواد النفسية، و. . . فرد من غير المعتمدين علي المواد النفسية، ويتراوح المدى العمري للعينة من (1 ا- - . سنة)، وتضمنت أدوات البحث استمارة المقابلة الأولية، ومقياس السلوك التوكيدي، من إعداد أ.د/آمال عبد السميع. أشارت النتائج إلي عدم وجود فروق بين المعتمدين وغير المعتمين على المواد النفسية في السلوك التوكيدي، أي أشارت النتائج إلى عدم وجود علاقة بين السلوك التوكيدي والاعتماد على المواد النفسبة.

الكلمات الدالة: (السلوك التوكيدي - الاعتماد على المواد النفسية).

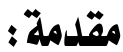

تعد مشكلة الاعتماد على المواد النفسية(1) واحدة من أخطر المشكلات النفسية والاجتماعية(Y) التى تقابل المجتمعات، وقد أصبحت مشكلةً عالمية منذ منتصف الستينيات من القرن الماضي وحتى الأن، وقد وصلت معدلات التعاطي إلى ذروتها عبر مسوح ويائية عديدة تمت فى عدد من دول العالم، وتكمن خطورة مشكلة اضطراب الاعتماد على المواد النفسية فى اقترانه بالعديد من المشكلات والأمراض الصحية الخطيرة مثل التهاب الكبد الويائي، ومرض فقدان المناعة المكتسب، واقترانه أيضًا بالعديد من مشكلات سوء التوافق النفسي والاجتماعي فى إطار البيئة الثقافية التى يعيش فيها الثخص المعتمد على المواد

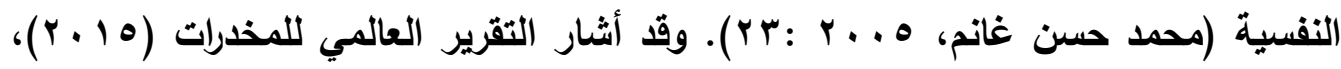

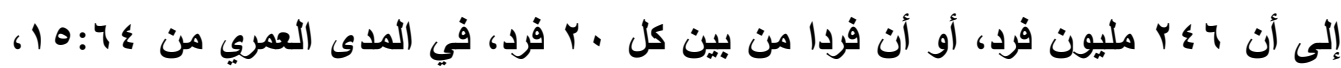

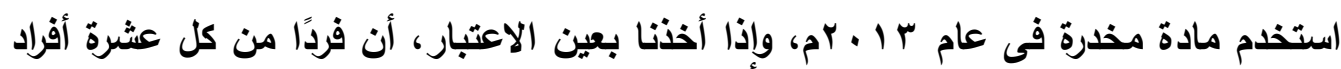

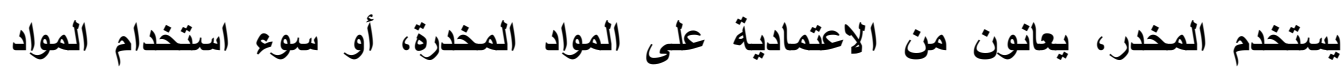

(1) Substance abuse disorder

(`) Psychosocial problems 
المخدرة،وهو ما يمثل TV مليون فرد يعانون، وهو ما يماثل تعداد دولة مثل ماليزيا)، ويشير التقرير إلى أن فردًا واحدًا من بين كل ستة أفراد يعانون من الاعتمادية على المواد المخدرة،

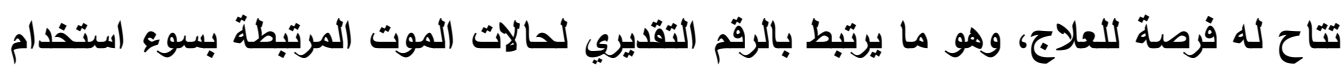

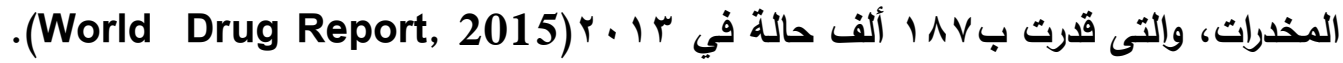
وقد قدم الباحثون عددًا من التفسيرات للجوء الأفراد إلى تعاطي المادة المخدرة، ومنها وجود بعض السمات الشخصية التي تساهم فى نشأة الاعتماد على المواد النفسية واستمراره؛ حيث يتسم المعتمدون على المواد النفسية بأنهم غير متزنين انفعاليًا وذاتيًا، وتتخفض لديهم الثقة والطمأنينة، ويبدو عليهم الثعور بالذنب، وعدم الاستقرار الانفعالي، وانخفاض تقدير الذات، باتهم وأنهز يواجهون في حياتهم المبكرة قدرًا من التوترات، وقدرة أقل على حل المشكلات، ويتصفون بالعدوانية في التعبير عن مشاعرهم، ومحاولة جذب انتباه الآخرين، ويميل بعضهم

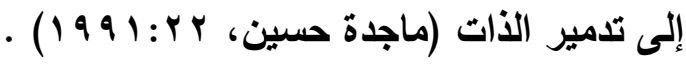

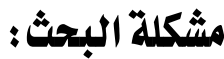

أكد مارلات أن هناك عددًا من المشكلات التى تؤدي إلى التعاطي أو العودة إليه، وتكمن في عجز الفرد عن رفض الضغوط الاجتماعية لبدء التعاطي، أو عجزه عن رفض مطالب الآخرين. وفي هذا السياق تثير نتائج دراسات سويف 19^v إلى أن الخضوع لضغوط الأقران من أهم العوامل المؤدية إلى بدء التعاطي؛ حيث وجد أن • V \% من عينة دراسته وقعوا تحت الضغط أو الإغواء من الآخرين سواء كانوا أصدقاء، أو أقرياء أو زملاء

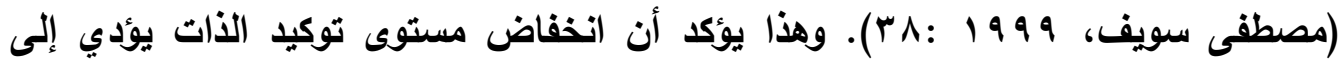
زيادة احتمال تورط الفرد فى أداء أنواع من السلوك المشكل منها الاعتماد على المواد النفسية، فإذا انخفضت قدرة الشخص على قول كلمة "لا" من باب الخوف من الآخرين، فقد

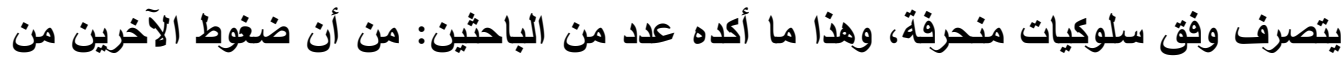

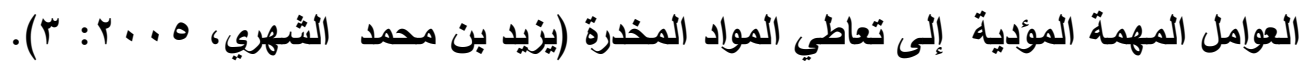
وقد بحثت العديد من الاراسات النفسية فيفروق السمات الشخصية بين المعتمدين على المواد النفسية وغير المعتمدين على المواد النفسية، وخلصت دراسة "تثالمرز" وآخرون (1991) إلى أن المتعاطين للمواد المخدره أكثر اندفاعية ومجاراة وخضوعًا عن غير 


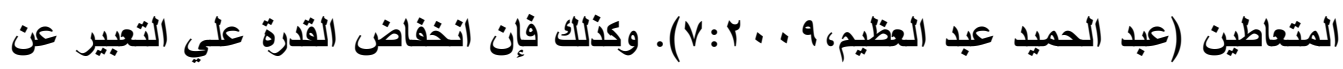
المشاعر يقود إلى الاضطرابات النفسية، وقد بين باترسون أن عدم القدرة على إظهار المشاعرالسلبية (الغضب) يؤدي إلى الاضطراب النفسي، وأن عدم اظهار المشاعر الإيجابيه بحسب رأي جامبريل تضعف علاقتنا بالآخرين، وكذلك إذا انخفضت قدرة الشخص على قول "لا" من باب الخوف من الآخرين، قد تعرضه للتصرف وفق سلوكيات منحرفة وهذا ما أكده

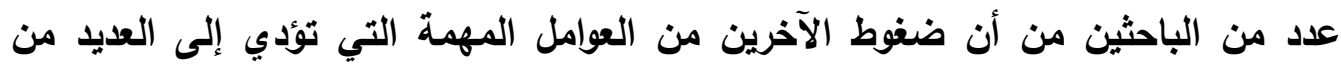


أجراها عام VI إهـ إلى أن ضعف التوكيدية من أهم العوامل التي تؤدي إلى تعاطي المخدرات والخمور والسلبية والعجز عن رفض مطالب الآخرين (غانم بن مذكر القحطاني، $\cdot(1 \cdot: 1 \leq \mu$.

وفي ضوء العرض السابق، يمكن صياغة مشكلة البحث الحالية في السؤال التالي: هل هناك فروق بين المعتمدين وغير المعتمدين على المواد النفسية فى السلوك التوكيدي؟

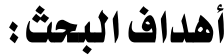

$$
\text { في ضوء العرض السابق يهرف البحث إلى: }
$$

- فهم طبيعة الفروق بين المعتمدين وغير المعتمدين علي المواد النفسية في توكيد الذات. - تفسير قرة السلوك التوكيدي علي التنبؤ بالاعتماد علي المواد النفسية.

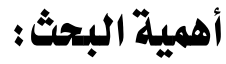


تثمثل الأهمية النظرية للبحث في: 1- المساهمة فى التأ صيل النظري لمفاهيم البحث، ونظرياته، والمصطلحات المتعلقة 
r - التحقق من الفروض النظريه للبحث، والوقوف على العلاقة بين السلوك التوكيدي في اضطراب الاعتماد على المواد النفسية.

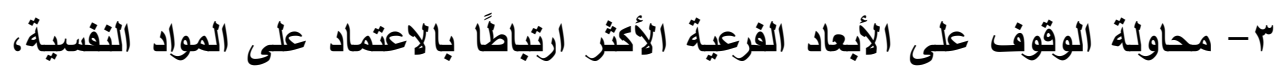

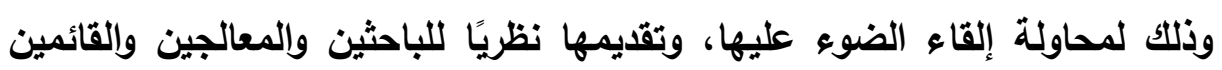
على برامج الوقاية. ثانيًا : الأهمية التطبيقية: تتمثل الأهمية التطبيقية للبحث في: 1 - إمكانية توظيف نتائج هذا البحث فى وضع برامج وقائية لمنع الاعتماد على المواد النفسية. r- إمكانية إعداد برامج إرشادية وعلاجية لتنمية مهارات توكيد الذات، ويخاصة مرضى الإلدمان. إلمان.

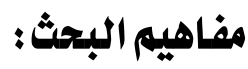

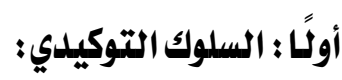
فى عام r · 19 كانت أول إثارة بصورة غير مباشرة لمفهوم توكيد الذات علي يا

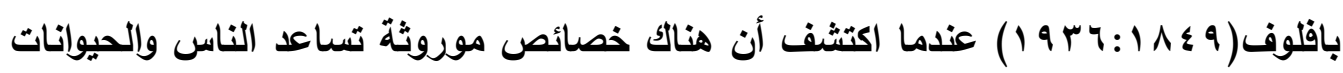

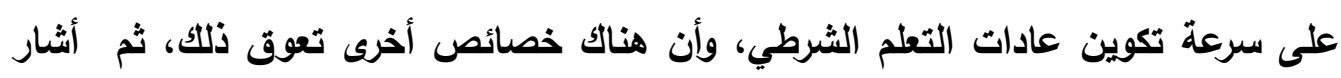



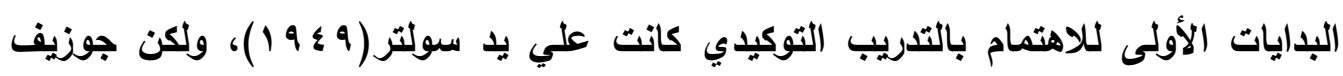
ولبى هو من أدخل فنية الاستجابة التوكيدية ضمن فنيات علاج المرضى الخجولين الذين لأين

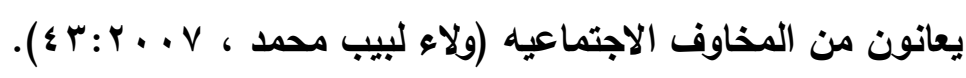
يوجد العدبد من التعريفات التي تناولت تعريف السلوك التوكيدي، ويمكن تلخيص هذه التعريفات على النحو يلي: 
- بعض هذه التعريفات لا يحتوي على جميع أبعاد السلوك التوكيدي، مما يسمح

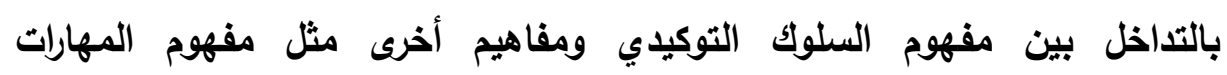

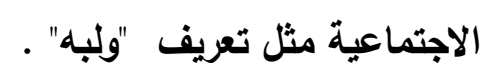

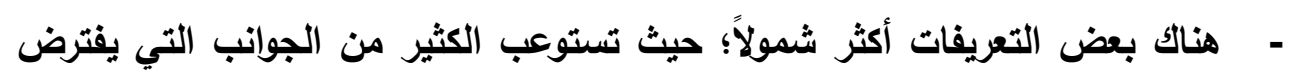
أنها متضمنة في السلوك التوكيدي مثل تعريف Rakos

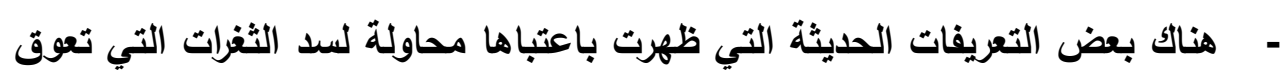
الإدراك السليم لهذا المفهوم مثل تعريف ( صابر أحمد عبد الموجود، 9 ، . ب ). - تشير بعض التعريفات إلي أن السلوك التوكيدي هو سلوك متعلم يشمل الجانب

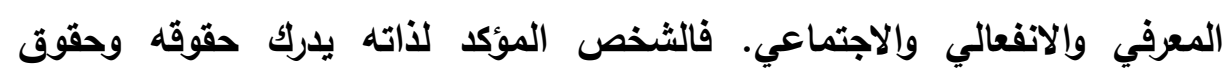
الآخرين، وايثق من نفسه، يسأل عما يريد، ويرفض ما لا يريد، يعبر عن انفعالاته بطريقة مناسبة، يتعامل بلطف وأمان مع الآخرين.

\section{ثانيًا : الاعتماد علي المواد النفسية:}

تعد مشكلة الاعتماد على المواد النفسية واحدة من أكبر المشكلات النفسية والاجتماعية التى تقابل المجتمعات، وقد أصبحت مشكلة عالمية منذ منتصف الستينيات من

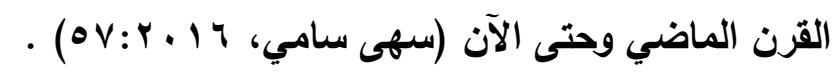

وعلى الرغم من الجهود المبذولة في جميع بقاع العالم لمحاصرة مشكلة

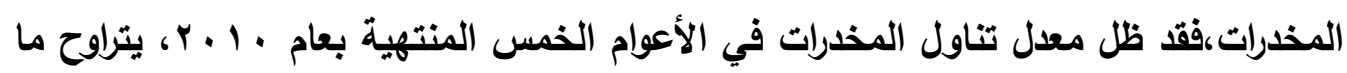

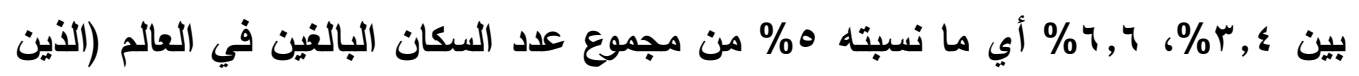

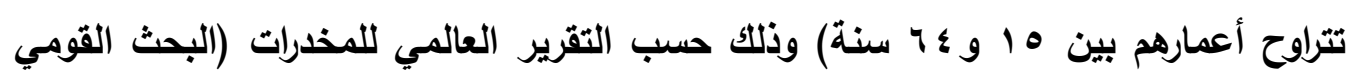

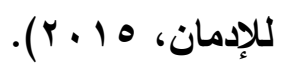

وفى مصر وفقًا لما جاء فى دراسة المجلس القومي لمكافحة وعلاج الإدمان، فإن ما

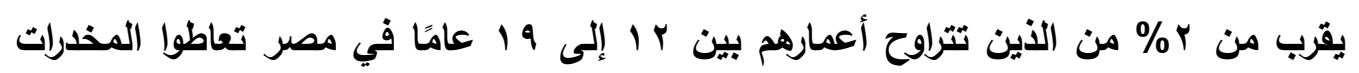

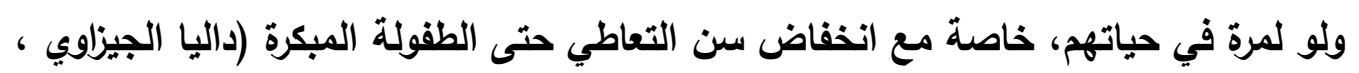

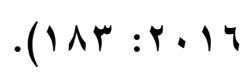




\section{المحكات التشخيصية لاضطراب الاعتماد على المواد النفسية}

يشيرالدليل التثخيصي والإحصائي الرابع للأمراض النفسيةأنه يستخدم تثخيص الاعتماد فقط إذا أظهر الثخص أو مر بثُلاثة أو أكثر من الأعراض الآتية: 1 - رغبة أو إحساس قهري بضروره تناول العقاقير. r - وعي ذاتي باختلال القدرة على التحكم فى سلوك تناول العقار سواء بدايته أو إنهاءه

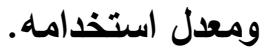

ץ- ب- تستخدم المادة المخدرة بغرض التخفيف من أعراض الانسحاب . ع - وجود حالة انسحاب فسيولوجية. ه- توافر دليل على حدوث التحمل، بمعني أن الثخص يحتاج دائمًا إلى زيادة جرعات المادة ليحصل على الأثر نفسه، الذى كانت تحدثه من قبل الجرعات الأوقل منها. צ- الإهمال المتزايد لأي متع أو اهتمامات بديلة لصالح العقار. V- المثابرة على استخدام العقار على الرغم من وجود دليل واضح على التبعات التهات الضارة سواء طبية أو اجتماعية أو مادية أو مهنية أو نفسية (من خلال سهى سامي، (American \& Psychiatric Association, 2000r. 14 ويجد الباحثون أن هذه الطبعة من الاليل التشخيصي قسمت الاضطرابات ذات الصلة

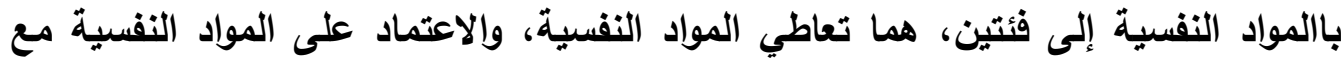
علم وجود حدود فاصلة بين التعاطي والاعتماد.ثم جاعت الطبعة الخامسة للاليل التثخيصي والإحصائي الخامس بمصطلح واحد جديد وهو اضطراب استخدام المواد النفسية.

\section{المفاهيم الإجرائية لمصطلحات البحث:}


توضح قدرة الفرد على التعبير الخارجي الحرعن انفعالات هو آرائه وحقوقه ومشاعره الودية التهاية والعاطفية، وغيرها من مثاعر الفرد، وإعطاء الأوامر والسيطرة على سلوكياته والضبط الذاتي والثقة بالنفس والتحدي والالتزام". وهو التعريف الذي سيتبناه الباحث في الدراسة الحالية.

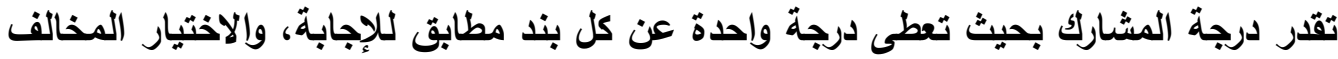




\section{الفروق في السلوك التوكيدي بين المعتمدين وغير المعتمدين علي المواد النفسية.}

صفر، وفي النهاية يتمجمع الدرجات في درجة واحدة تعبر عن الدرجة الكلية للسلوك التوكيدي.

الاعتماد على المواد النفسية: يعرفه مصطفى سويف (999 19) بأنه "حالة نفسية

وأحيانًا عضوية، تتتج عن التفاعل بين الكائن (الحيوان أو الإنسان) والمادة النفسية. وتتسم هذه الحالة بصدور استجابات سلوكية وفيسيولوجية تنطوي دائمًا على قهر للكائن أن يتعاطى الأن هذه المادة على أساس مستمر أو متقطع، وذلك طلبًا لآثارها النفسية، وأحيانًا تحاشيًا لما يترتب على غيابها من متاعب. وقد يعتمد الشخص على مادة وإحدة أو عدة مواد في آن

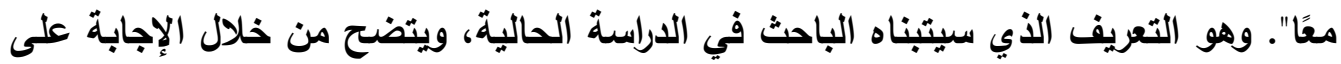
استمارة المقابلة الأولية.

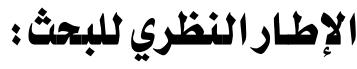

\section{النظريـات المفسرة للسلوك التوكيلدي:}

ويرى كاي أن سالتر يعد من أبرز من وظف قوانين بافلوف في التعلم والعلاج السلوكي، مستتدًا إلى الاستثارة والكف، ولقد ميز سالتر بين نوعين مهمين من السلوك في هي في

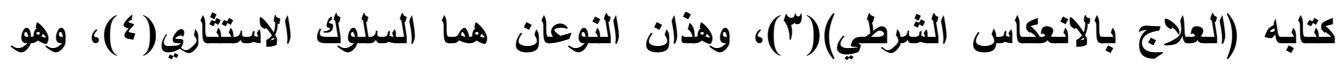
السلوك الذي يتصف صاحبه بمهاجمة الآخرين أثناء التعبير عن مشاعره، والسلوك الانكفافي(ه)، ويتصف صاحبه بأنه غير قادر على إقامة علاقات مع الآخرين بصورة

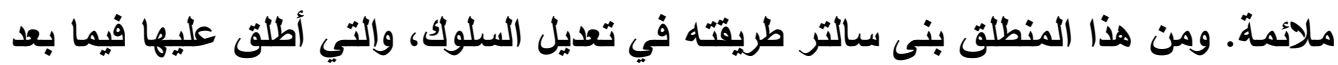

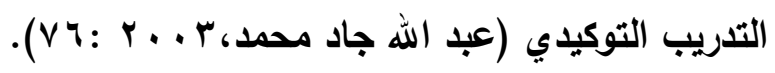

وتثير العديد من الدراسات إلى أن من العوامل التي تؤثثر على السلوك التوكيدي

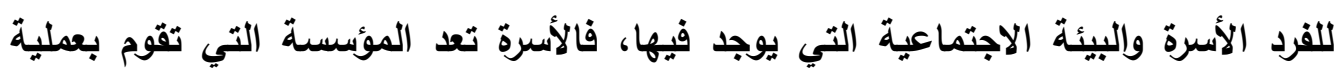

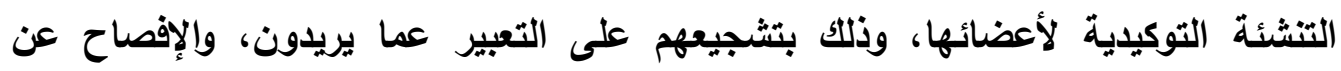
وجهات نظرهم في القضايا المختلفة، وتدريبهم على التحاور فيما بينهم، ولذلك فإن أساليب

(3) Conditonal Reflex Therapy

(4) Excitatiry Behavior

(5) inhibitiory Behavoir 
المعاملة الوالدية تؤدي دورًا بارزًا في اكتساب الأبناء للمهارات التوكيدية، وتساعد على ارتقائها إذا سارت في الوجهة السليمة التي تحث على التوكيد، كما أثارت بعض التهات الدراسات

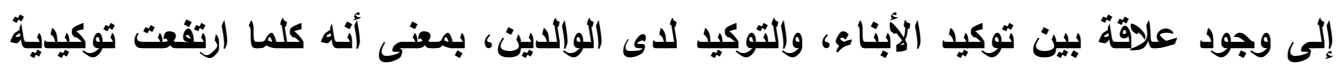

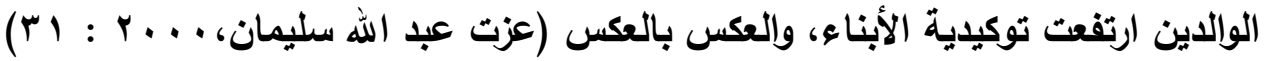

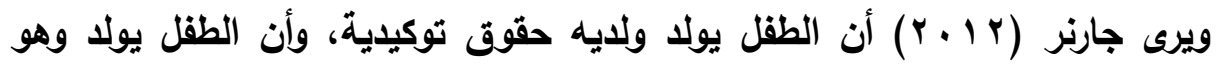
بفطرته منفتح على العالم وودود، ويبادله العالم هذا الحب، ولكن مع تنامي العقل لدى ئى الطقل، تزداد مخاوف المهتمين به، لما يدركونه من أخطار في العالم، وهو لا ياركها بعد، فيبأون في تعليم الطفل استراتيجيات، من وجهة نظرهم ستعمل على حمايته من الأخطار المحيطة، فيبدأون في تعليمه أساليب غير توكيدية، ويرى "أريك" أن توكيدية الطقل لا تنتهي،

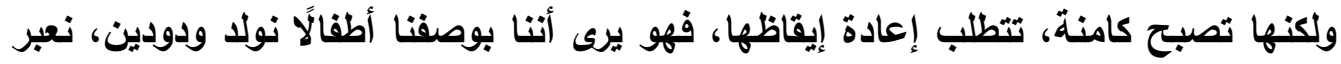
عن مشاعرنا بأريحية، وننقتح على العالم بسهولة، ونثق بالآخرين بلا شروط مسبقة، ونعيش تمامًا في الحاضر، ثم يبدء العقل في التكوين، ويتعامل الطفل مـع العالم بتلك البراءة نفسها، فتعمل الأساليب الوالدية على إمدادنا بقوائم افعل ولا تفعل، ويبدأ الطفل في استبدال التفكير الحذر ببعض من عفويته، ويستبدل ما يجب أن يقوله ليحصل على ما يريد بتواصله البريء الفطري، ويتعلم أن "الخزي" و"اللوم" أجزاء رئيسة في هذه الحياة، ويتبنى الآباء بما لهم من خبرة في الحياة وآراء معينة في مقابل عفوية الأطفال، فيتعلم الطفل التفاوض بدلًا من الطلب بعفوية، ويستبال التواصل غير الأمين بالتواصل الأمين أحيانا للحصول على ما ماله يريد، يستبدل الحب المشروط بالحب غير المشروط، ويناءً على ما سبق يستبال الطقل

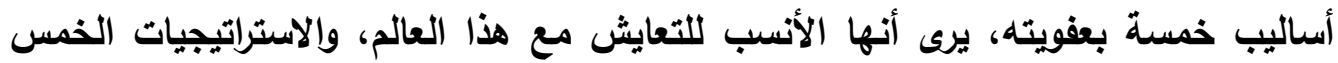

اللوم: يتعلم الفرد أنه للحفاظ على نماذج الحب في هذه الحياة، ويالأخص عندما يخطئ، فإن عليه أن يلوم إما نفسه أو الآخر، فيدخل في دائرة من كونه خاضعًا وعدوانيًا، وتبقى لعبة اللوم إحدى الوسائل للحفاظ على نماذج الحب.

النفس الزائفة: يستبدل الراثد أنماطًا أخرى من التفكير بعفويته للحماية، مثل: 
الفروق في السلوك التوكيدي بين المعتمدين وغير المعتمدين علي المواد النفسية.

$$
\text { - الآخرون لا يتغيرون إلا بالنقا. }
$$

- غضبك سيظهر للآخرين أنك على حق، وأنهم هم المخطئون.

$$
\text { - الانتقام يسمح بتحقيق العدالة. }
$$

- من الضعف أن تترك نفسك عرضة للفهم من الآخرين.

- الحكم على الآخرين إحدى ملامح قوة الشخصية.

- يمكن للفرد حماية نفسه بالهجوم على الآخرين، أو التهايد بسحب الحب، والتهكم

بهم من خلال الخوف، الأتب، الخزي.

- خداع ومناورة الآخرين يساعد على النجاح.

مربع "بخير": لو تخيلنا شكل العلاقات مع الآخرين، سنتمكن من تقيم مربع إلى

أريعة أجزاء، الجزء الأول منه سيصبح: لو ندئ

- يمكن أن نشعر بخير بخصوص أنفسنا، ولكن ليس بخصوص الآخرين "الأسلوب

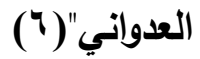

- يمكن أن نشعر الآخرين بالخير، ولكن لا يمكن أن نشعر أنفسنا "الأسلوب

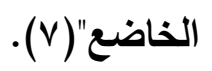

- لا يمكن أن نشعر أنفسنا أو الآخرين بالخير "الأسلوب الاكتئابى"(^). - يمكن أن نشعر أنفسنا والآخرين بالخير "الأسلوب التوكياي"(9). ويرى "إيريك" أن الأسلوب التوكيدي يختفي خلال سنوات التشئة، ولكنه يكون كامنًا لا يختفي للنهاية. - - نمط الشخصية: ويرى "إيريك" أنه بنهاية المطاف، يتكون لاى الفرد نمط معين من الشخصية (Garner,E, 2012, 16).
(6) Aggressive mode
(7) Supmessive Mode
(8) Depressive Mode
(9) Assertive Mode 


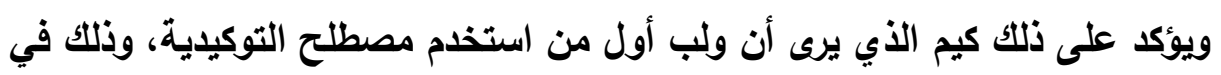

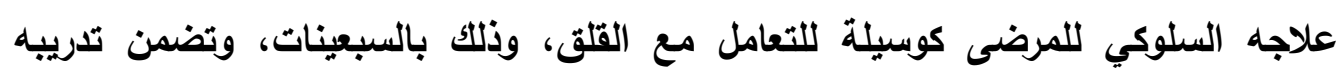

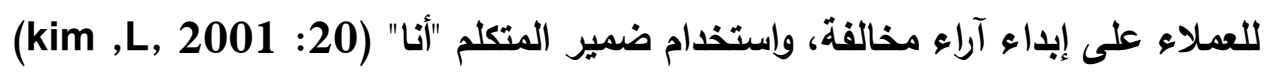

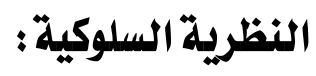

تعرف عدم توكيد الذات بأنه سلوك متطلم يمكن فهمه وتفسيره فى ضوء مفاهيم

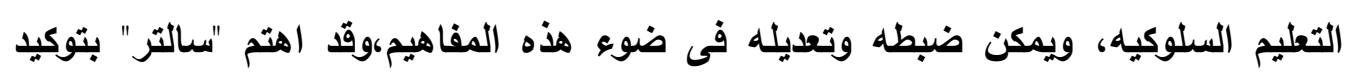

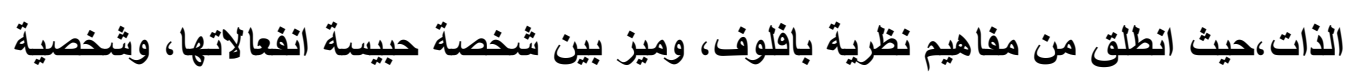
أخرى تلقائية إيجابية، ويرى سالتر أن كل الاضطرابات النفسية ناتجة عن الكبح

\section{نظرية العلاج العقلي والعاطفي: Rational -Emotive Therapy}

يمثلها "اليس" ويري أن الأفكار وإلمعتقدات غير العقلانية لاى الأفراد تُنْهُرُ بشكل

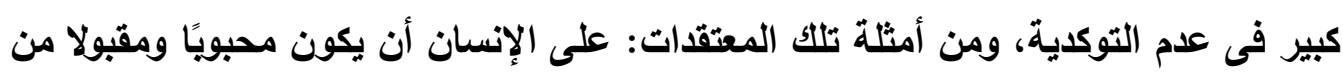



\section{نظرية التعلم الاجتماعي: Bandura Theory Of Social Learning}

أثشار العالم "باندورا" فى هذه النظرية، إلى التأثيرات القوية للنماذج على الأطفال،

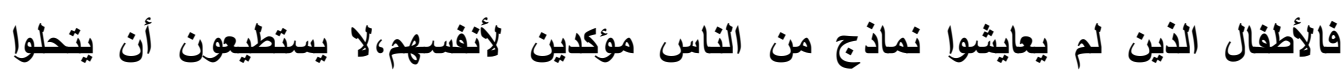

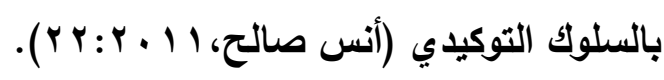

\section{مكونات وأبعاد السلوك التوكيلى}

ويري طريف شوقي (9 १ (1)) أن المكونات اللفظية للسلوك التوكيدي هي كالآتي:

$$
\begin{aligned}
& \text { 1- التوكيد الاجتماعي } \\
& \text { ז- الدفاع عن الحقوق } \\
& \text { r- القيادة والتوجيه } \\
& \text { ع - الاستقلال }
\end{aligned}
$$




\section{الفروق في السلوك التوكيدي بين المعتمدين وغير المعتمدين علي المواد النفسية. \\ وتتضمن المكونات غيراللفظبة الآتي:}

1 - مظاهر فسيولوجية داخلية، مثل العمليات اللفظيةكالنبض، وضغط الدم، تقلصات المعدة، ومن الصعب بصورة عامة رصدها

$$
\text { r - مظاهر سلوكية خارجية: }
$$

ب- الابتسام:عدد الابتسامات الملائمة للمواقف التى يصدرها الفرد

ج- مدة الاستجابة:الفترة التي يتكلم فيها الفرد فى كل موقف من المواقف التي تتطلب

$$
\text { الكلام، وتحسب بالثثاني }
$$

د- كمون الاستجابة: الزمن المنقضي منذ صدور المثير وحتى إصدار الاستجابة هـ -شدة الصوت:من المتوقع أن الصوت الواضح يعكس قربرامن التوكيدية

و - ارتباك الكلام:يعبر عن نسبة التلعثم والتوقف اللا إرادي نسبة إلى المحتوى الكلي

$$
\text { للكلام }
$$

ز - الصمت: قد يستخدم لرفض إلحاح الآخر

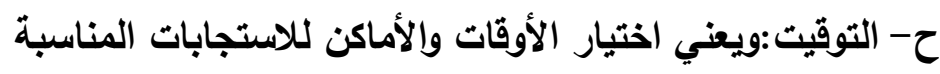
ط- وضع الجسم:الجسم المسترخي يعكس قدرًأكبر من التوكيدية

التعبيرات الوجهية: يستدل منها على الحالة الانفعالية والتوكيد (طريف شوقي فرج،

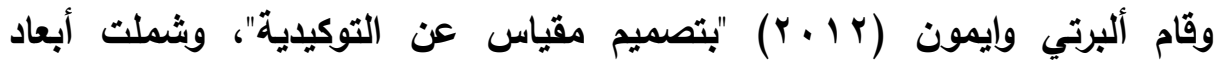

$$
\text { المقياس الجواتب الآتية: }
$$

- قدرة الفرد على التعبير عن مشاعره وتفضيلاته

$$
\text { - القدرة على التصدي للحقوق }
$$

- اظهار الاحترام للآخرين حتى فى مواقف الخلاف - - التعبير عن المشاعر الإيجابية للآخرين

$$
\text { - - الإبقاء على تواصل العين }
$$


الفروق في السلوك التوكيدي بين المعتمدين وغير المعتمدين علي المواد النفسية.

- قدرة الفرد على تعريف ذاته (Kelly,B,2015:9)

وقد حدد "راكوس 1991 أربعة أبعاد للسلوك التوكيدي هي:

- المحتوى:"يتضمن محتوى الكلام الذي يقوله الثخص المؤكد للآخرين"

- خصائص اللغة: وتتضمن"تبرة الصوت،علو الصوت، مدة الاستجابة،طلاقة الكلام،

- المهارات غير اللفظية: وتتضمن (حركة الجسم،التواصل بالعين،عبيرات الوجه،

الإيحاءات، المهات

- مهارات التفاعل الاجتماعية: وتتضمن المبادأة والإصرار، وتعزيز الاستماع الإيجابي

من الطرف الآخر (kim,I,2001:23).

ي- نظريـات تفسير الاعتماد على المواد النفسية:

التفسيرات البيولوجية لتعاطي المخلدرات:

نموذج الإدمان باعتباره مرضًا يركز على الاستعدادات الجينية للفرد، وعلى الغلل

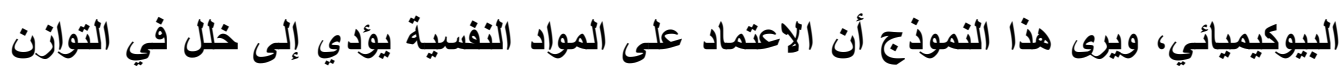

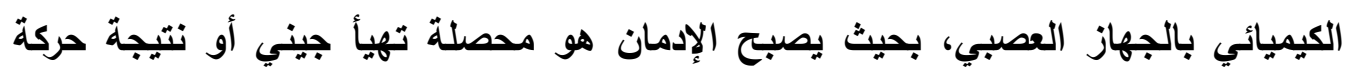
كيميائية أثرت على المخ (Adeina,D,2007:2).

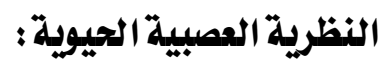

تشير تلك النظريةإلى تظور الاعتماد على المواد النفسية بالرجوع إلى العمليات

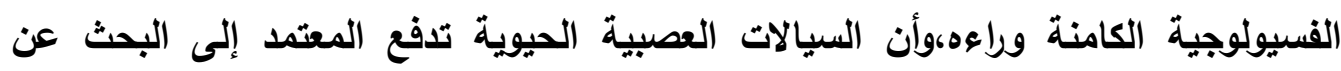
المخدر،ويتكيف المخ مع تلك المنبهات والمثيرات من المواد المخدرة،يث يعمل بنظام الإثابةأو المكافأةالعصبية لتلك المواد،وقد اكتشِفَ نظامُ الإثابة في المخ على يلى يد العالم أولدز § 90 ا،ويعد نظام الإثابة من أكثر العوامل البيولوجية العصبية/الأساسية التي تؤدي دورًا فى التهيؤ للإصابة باضطراب الاعتماد على المواد النفسية،وأن هناك ممرات لهذا النظام وهى الإنى الناقلات العصبية الدويامينية،والدويامين مادة في الجسم منشطة للجهاز العصبي،وقد تبين 
وجود خلل في مستقبل الدويلمين لاى العديد من المعتمدين على المواد النفسية (سهى سامي .$(70: Y .17$ ،

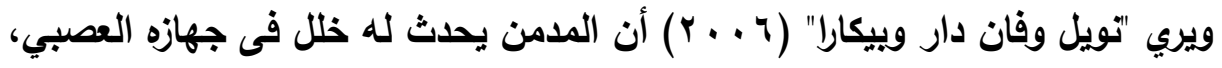

الذي يرسل إثارات الألم أو السعادة إلى سائر الجهاز العصبي، الذي بدوبل بدوره ينتقي الاستجابات، ولاحظوا أن الأشخاص غير المدمنيين الذين يتعرضون لإصابات في المنطقة

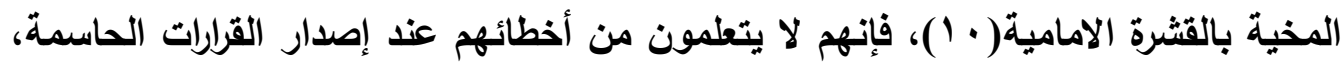

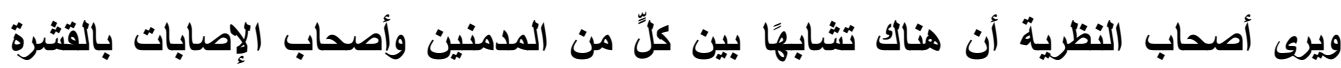
المخية، فكلاهما ينكر وجود مشكلة لايه، ولا يستطيعون حساب عواقب أفعالهم، كما أن ميكانزمات اتخاذ القرار عندهم يبدو أن بها خلل، ويتحول المعتمدون على المواد النفسية من لن الإدارة الأتية للسلوك(1 (1) إلى السلوك الآلي للإشباع الحسي(r ( )، وتمكنت المسوح الطبية بالآثعة على المخ(ب آ)، من اكتشاف خلل في وجود القدرة بالمخ على اتخاذ القرارات، نتيجة الحاجة القهرية لتعاطي المخدر أو العقار، ويصبح عند المتعاطي خلل فى اتخاذ القرار، وسلوك قهري لتعاطي المخدر، وهكذا يدور المعتمد فى دائرة مفرغة لإدمانه، ويكون الإنكار هو الرفيق الأكثر للإدمان، فيبقى الثخص في دائرته الإدمانية، ويساعده الخلل في القدرة على التعلم، والدافعية، واتخاذ القرارات، على البقاء في الدائرة نفسها :West, R, 2005).

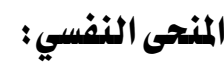

ويرى فرويد أن السلوك الإدماني قد يكون محاولة للهروب من ظروف بيئية مرعبة،

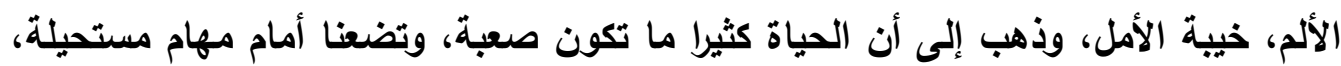
ورأى أنه بالتعرض لتلك المواقف الصعبة، قد يلجأ بعضهم إلى إجراءات التسكين، وهى ثثلاثة: الانحرافات القوية، الرضا السلبي، المواد المخدرة، وأى جولفر ب ب أن أن السلوك الإدماني

(10) Ventro Medical Prefrontal Cortex

(11) Self-dircted behavior

(12) Automayic sensory-driven behavior

${ }^{(13)} \mathrm{MRi}$ 


\section{الفروق في السلوك التوكيدي بين المعتمدين وغير المعتمدين علي المواد النفسية.}

يوجد للسيطرة على رغبات سادية، أو نزعات مثلية أو لكنع النكوص المؤدي إلى فصام .(Bernadette \& ZosIt, 2012: 3)

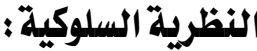

تفسر النظريه السلوكيه ظاهرة التعاطي والإدمان على ضوء عدة قوانين من أهمها: 1- قانون الأثر: فكلما حُصِلَ على إثباع في مواقف متمثلة في تعاطى المخدر، وأدى

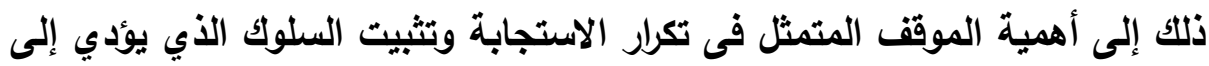

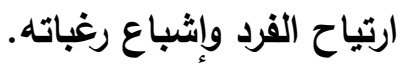
ץ- التكرار: يؤدي تكرار سلوك تعاطي المخدرات إلى تثبيته وتدعيمه، خاصة إذا كانت الخبرات الناتجة من هذا السلوك فيها إثباع للحاجات. ץ- التغزيز: فعدم وجود معوقات عند قيام الفرد بسلوك معين يشبع رغبة ويثبت السلوك،

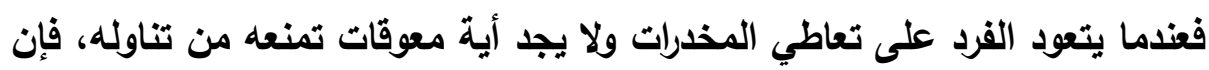
هذا يثبع رغبته ويدفعه إلى تثبيت ذلك السلوك.

ع - تقوية العادة: قد تقوى العادة الضارة عندما يهتم القرد بذاته دون النظر إلى معايير

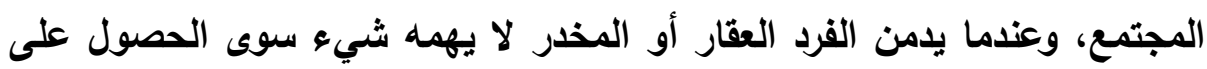

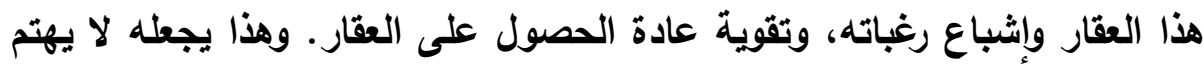

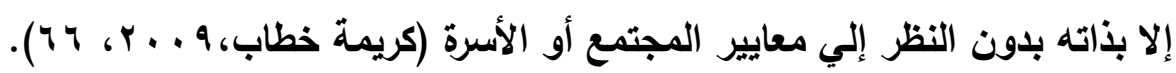

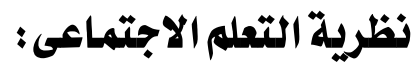



افترض "وكلر" أن عوامل الأثراط تؤدي دورًا مهمًا فى إدمان العقاقير والمخدرات، ولذلك لوحظ أن الحيوانات يزيد عندها معدل الاستجابة القائمة على الأثراط الإجرائي،حينما تتبع هذه الاستجابات بالحقن بمشتقات الأفيون أو منبهات الجهاز العصبي مثل الأمفيتامينات

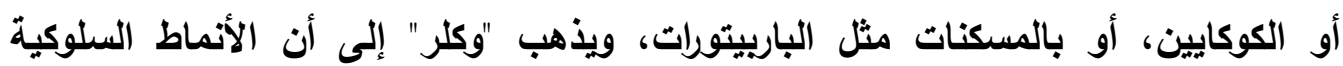
والأثشياء المتعقة بتعاطي العقاقير والمخدرات تصبح معززات ثانوية، نتيجة للتزاوج المتكرر

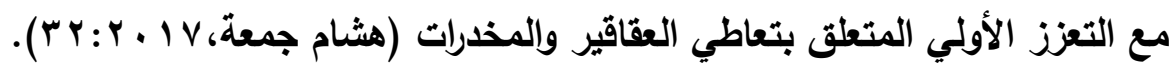




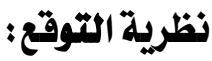

التوقعات عمليات معرفية تتعلق بريط الأحداث أو بثكل أدق تتوقع النتائج المترتبة على أحاث معينة، ومن خلال قواعد التعلم يتعلم الفرد أن يتوقع العلاقة بين الأحداث أو أو الموضوعات فى موقف قادم، ويالنسبة لنظرية التوقع في تفسير الإدمان ترى أن ما يتعلمه الفرد هو العلاقة بين استخدام المادة والنتائج المرغوية أو المعززة، وذكر جولامان وآخرونة أن مدمني الكحول من المراهقين يختلفون عن غير المدمنيين في توقعاتهم تجاه ما يقدمه المدان

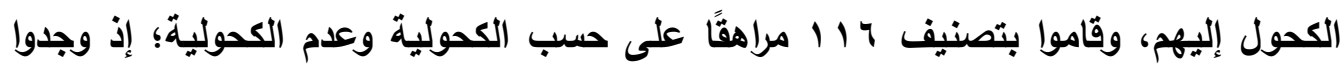
فروقًا بين المجموعات الأربعة فيالتوقعات المرتبطة بالتعاطي؛ إذ توقع المراهقون الذين الذين

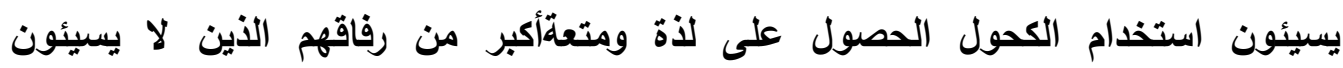

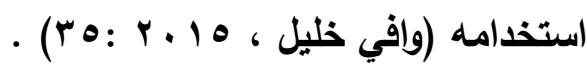

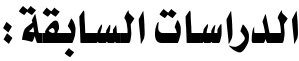

هافت دراسة "ستينر ولوسلي (911) إلي قياس مدى فاعلية برنامجللتريبعلى

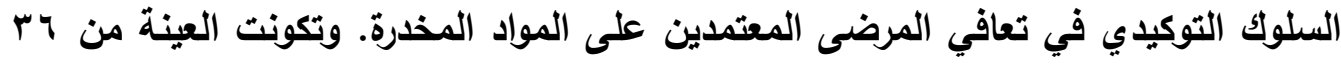

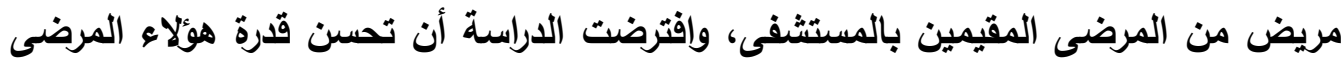

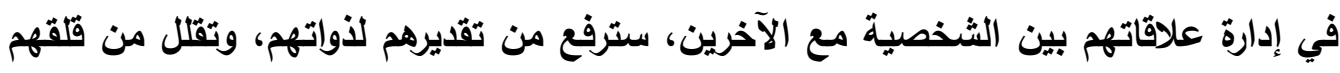
الاجتماعي، وستزيد من الفترة الزمنية للتعافي من المخدرات، وتقليل السلوكيات غير المرين المرغوني

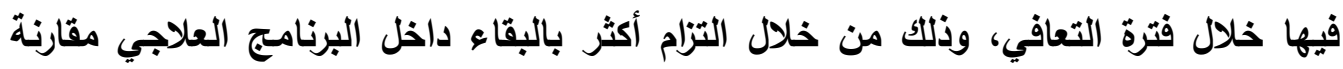
بغير الخاضعين للبرنامج التوكيدي، وأن يكون تقييم المشرفين لهم أفضل من حيث الالتئل

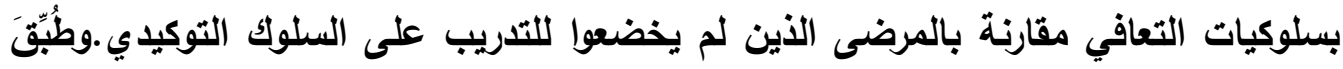

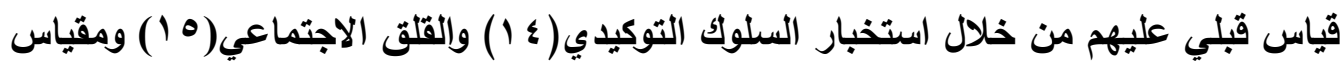
مفهوم الذات واختبار التوكيد السلوكي(1 1 (1). وتدريوا على السلوك التوكيدي من خلال ثلمان

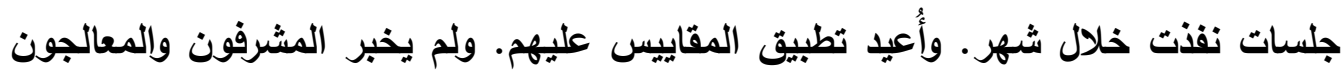
عن الأفراد المشتركين وغير المشتركين بيرنامج التدريب على التوكيدية. وطلب من المشرفين

(14) Assertion Questionnaire

(15) Social Anxiety Scale

(16) The Behavioral Assertion Test. 
تقييم جميع النزلاء من حيث مظاهر السلوك التوكيديفي أثناء تفاعلاتهم مع الأقران ومع المشرفين، وكثفت النتائج عن أن المجموعة التجريبية (من تعرضوا للتريب التوكيدي) كانوا أكثر توكيدًا من أفراد المجموعة الضابطة وذلك بالملاحظات من خلال القائمين على رعايتهم، ولكن لم يكن هناك فروق كبيرة على المقاييس الإحصائية بين المجموعة الضابطة والتجريبية

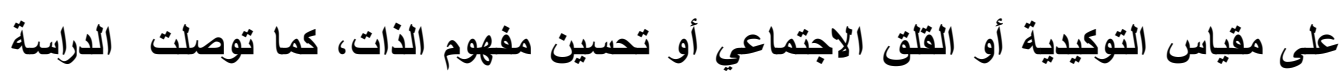

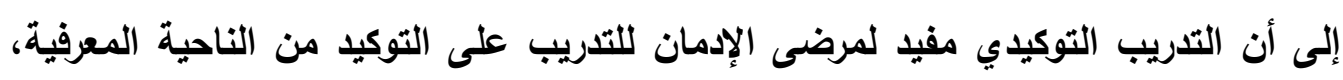

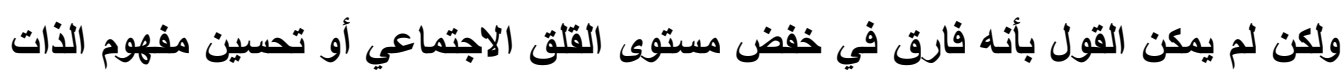
.(Steiner, C, Lucille, J, 1981)

كما هدفت دراسة نيلسون وإيريك (1919 1) إلى معرفة مدي تأثير التدرييب التوكيدي

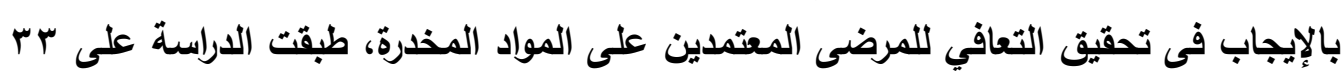
مريض من الأكور، الذين شُخصوا معتمدين على المواد النفسية، قسم المرضى إلى ثلى الثاثة

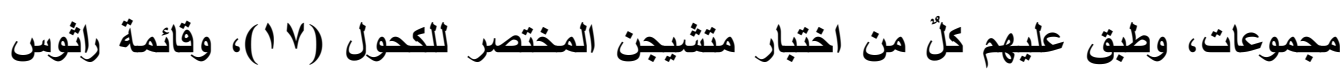

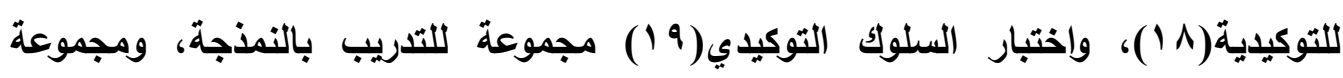
للتدريب بأداء الأدوار، ومجموعة ضابطة، خضعت المجموعتان إلى واحد وستين ساعة التهارية

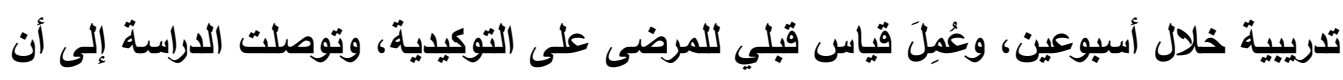

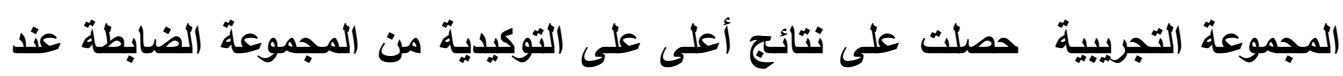

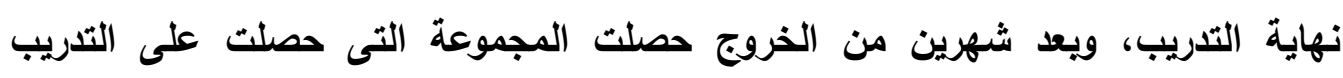

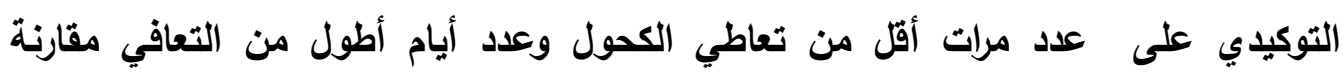

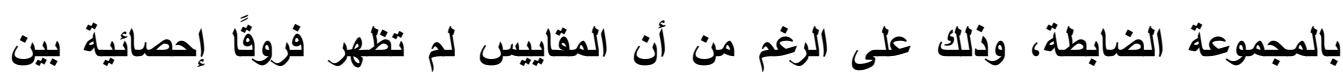
المجموعتين (Nelson E,1982 ).

وهدفت دراسة دانا ورويرت كوين (ع 9 1 ) ) إلى معرفة إذا ما كان لمقدار التوكيدية

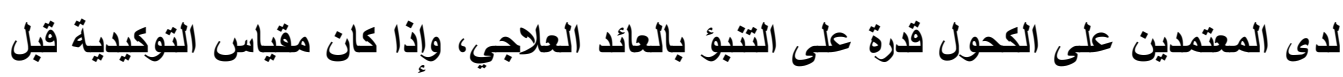

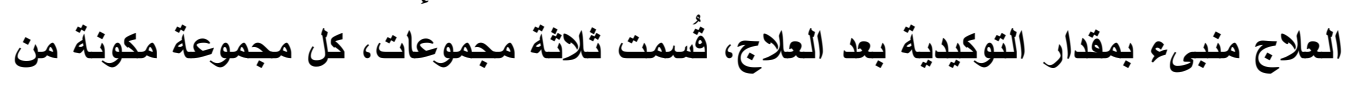

(17) Short Michigan Alcholism Screening test

${ }^{(18)}$ Rathus Asseriveness Schedule

${ }^{(19)}$ Behavioral Assertiveness Test 


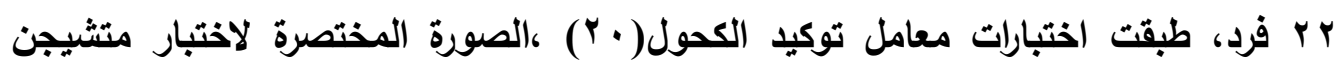
للكحول(Y Y)، طبق قياس قبلي ويعدي، وأشار معامل ارتباط بيرسون إلى أن الأفراد أصحاب درجة التوكيد الأعلى فى القياس القبلي على التوكيدية، كان المردود العلاجي لديهم أفضل من

أصحاب الارجات الأقلّ على التوكيدية في القياس القبلي (Dianne S S, (1991) وهدفت دراسة "اثبي وياكر Ashby \& Baker 198 " إلى الكثف عن العلاقة بين أبعاد التوكيدية، واستخدام المواد المخدرة، وذلك على عينة من طلاب المدارس الثانوية،

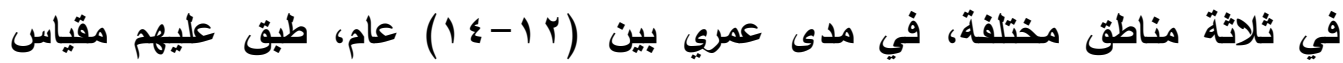
جامبريل - ريتشي للتوكيدية(Y Y)، وأظهرت الدراسة ارتباطًا عكسيًا بين البعد الفرعي للتوكيدية (التوكيدية الخاصة باستخدام المواد المخدرة، وبين استخدام المواد المخدرة، Ashby, T (

Barker, E, 1989)

كما أجرى "دياني" (1991 (19) دراسة هدفت إلى الكثف عن مدى فاعلية التدريب علي السلوك التوكيدي فى علاج مرضى الإدمان المتابعين بالعيادات الخارجية لعلاج الاعتماد على

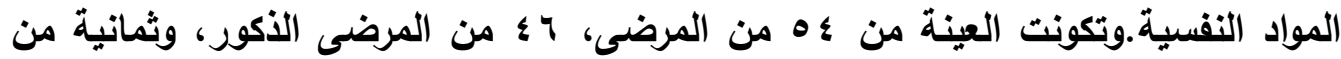


نفسه، أو من جهة العمل، وطبقت عليهم أدوات الدراسة عند باية البرنامج العلاجي، وعند انتهائه، ويعد ستة شهور من الانتهاء من البرنامج العلاجي. وكانت أدوات الدراسة هي:

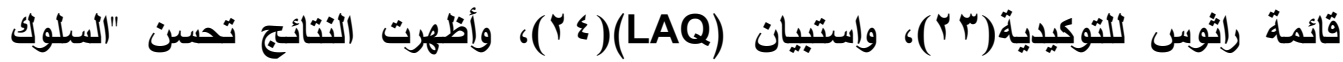
التوكيدي" من خلال المقارنة بين النتائج من إعادة تطبيق الاختبارات، وأكدت نتائج البحث أهمية برامج التدريب السلوكي فى برامج علاج الإدمان (Dianee ,S, 1991$).$ هدفت دراسة "جفاري و شاهيدى" (9 . . ب) إلى المقارنة بين السلوك التوكيدي، ووجهة الضبط، والصحة العامة، بين الثباب الذين شُخصوا على أنهم معتمدين على المواد النفسيةبين الثباب الصغار في إيران، وتكونت العينة من مجموعات ثلاثة من الثباب

(20) Assertion Inventory76 Alchol

(21) Short-Form Michigan Alcoholism Screening Test

(22) Gambril-Richy Assertion Inventory

(23) Rathus Assertiveness Schedule

${ }^{(24)}$ Life Area Questionnaire 
الإيرانيين، تكونت المجموعة الأولى من · r شاب من المعتمدينعلى المواد المخدرة، والذين

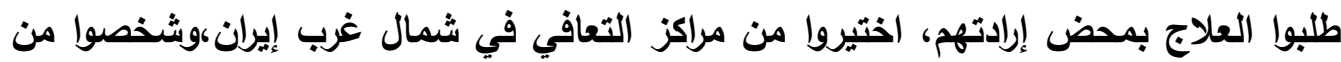

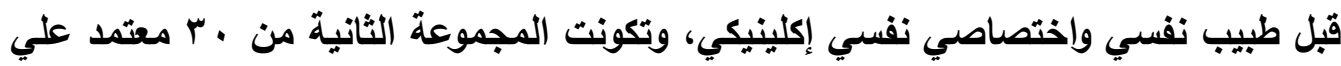
المخدر اختيروا من داخل أحد السجون بإيران، والذين صدرت بخصوصهم أحكام

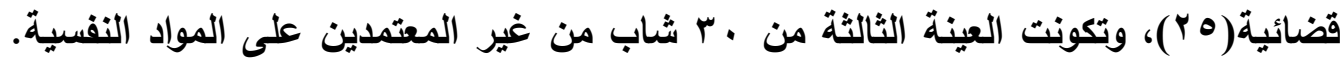

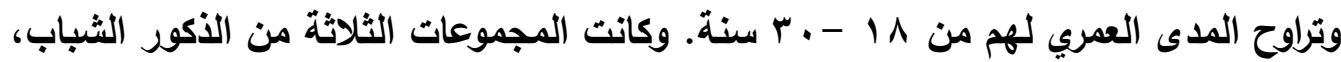
وروعي التجانس بين المجموعات. واستخدم الباحثون استبيان السلوك التوكياي(بَ) "لازوراس"، ومقياس وجهة الضبط(YV) ومقياس الصحة العامة (يضم أبعاد الثكاوى

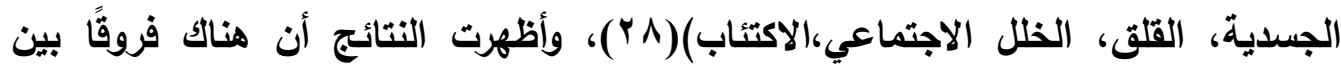

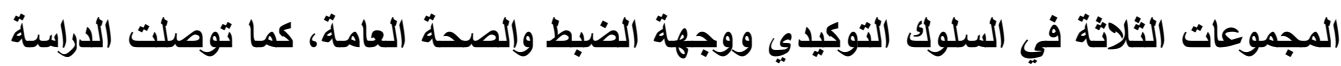
إلى أن غير المدمنين أعلى في السلوك التوكيدي وأن وجهة الضبط لايهم داخلية ولديهم

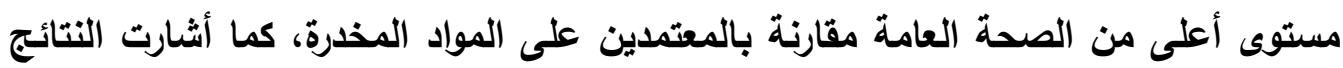
إلي أن المشاركين في مجموعة السجن أقلت أكيدا، وحصلوا على درجات منخفضة في مستوى الصحة العامة من مجموعة غير المعتمدين على المواد النفسية، كما أن وجهة الضبط لايهم كانت أكثر خارجيةً.

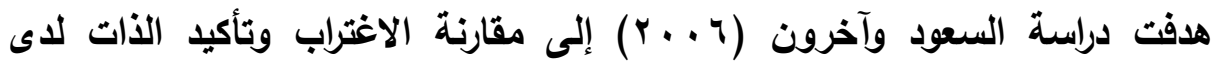

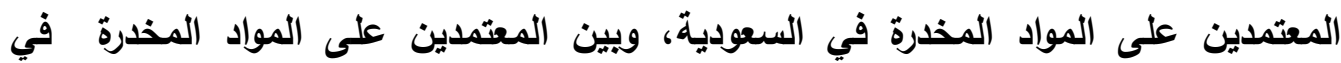
المملكة المتحدة، وخلصت الدراسة إلى وجود علاقة دالة بين استخدام المخدرات فى إنجلترا ويين انخفاض الارجة على توكيد الذات، في حين لم يكن هناك ارتباط في البيئة السعودية (

Al Saud, A\& Saud, B, 2017)

(25) The Ardebil Magistrate Court for addiction .

(26) Lazarus Assertiveness Test

${ }^{(27)}$ Locus of control test

${ }^{(28)}$ General Health qustionaire 




توجد فروق ذات دلالة احصائية بين متوسطي درجة المعتمدين وغير المعتمدين علي المواد النفسية على اختبار السلوك التوكيدي لصالح غير المعتمدين على المواد

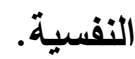

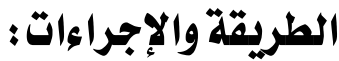

المنهج: المنهج الوصفي الارتباطي المقارن؛ حيث يهتم البحث باختبار الفروق بين المعتمدين وغير المتمدين في السلوك التوكيدي. العينة: تكونت عينة البحث من مجموعتين،نعرض لكل منهما على النحو التالي:

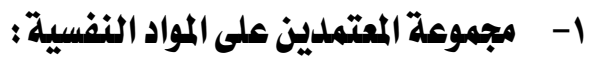

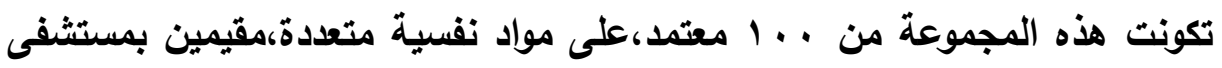

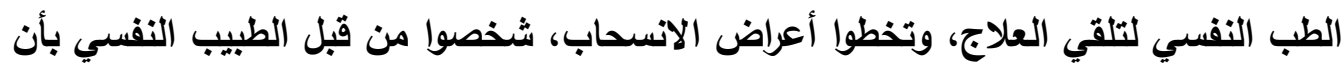



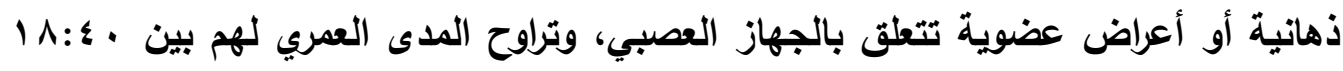

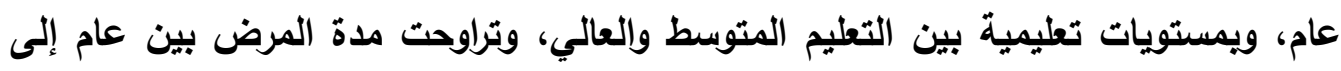

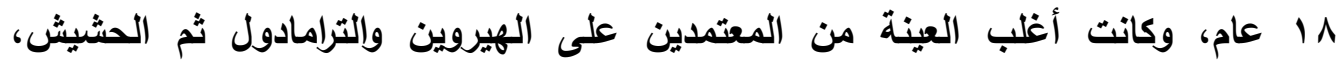


انتكاسة، وتراوحت عدد مرات الاخول ما بين مرة (أول مرة) إلى عشرين مرة، وتراوحت مرات

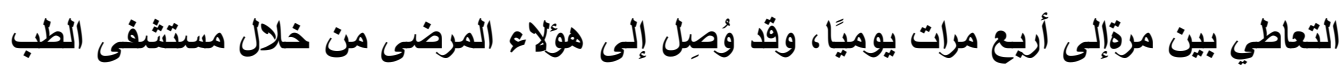
النفسي.


تكونت هذه المجموعة من .1 مبحوث من غير المعتمدين على المواد النفسية

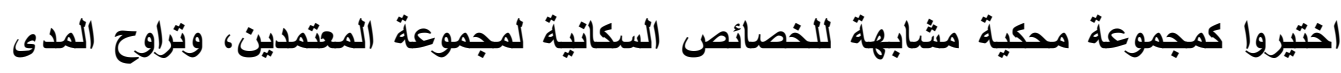


العمري لهذه المجموعة من · ؛ 1 1 سنة، ولم يسبق لهذه المجموعة الإصابة باضطرابات نفسيةأو التردد على المستشفيات أو العيادات النفسية. جدول (1) المتوسطات والانحر افات المعيارية للسلوك التوكيدي لأل المعتمدين وغير المعتمدين

\begin{tabular}{|c|c|c|c|c|c|}
\hline \multirow{2}{*}{ قيمة ت } & \multicolumn{2}{|c|}{ 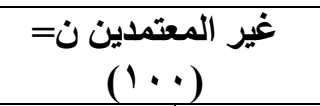 } & \multicolumn{2}{|c|}{ المعتمدين ن= ( · ( ) } & \multirow{2}{*}{ المتغير } \\
\hline & الانحراف & المتوسط & الانحراف & المتوسط & \\
\hline 1.741 & $r$ & 1.9 & Y. & 9.8 & التوكيدوي \\
\hline
\end{tabular}

ويتضح من الجدول ( ) تقارب متوسطات المتغيرات بين المعتمدين وغير المعتمدين

على المواد النفسية.

: الأدواتُ

مقياس السلوك التوكيدي:

مقياس السلوك التوكياي، من إعداد أ.د.آمال عبد السميع (......)، وتكون

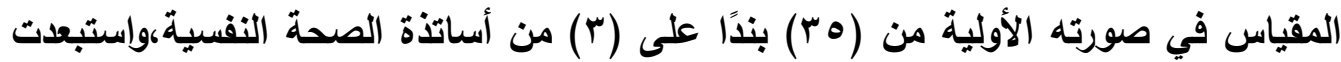

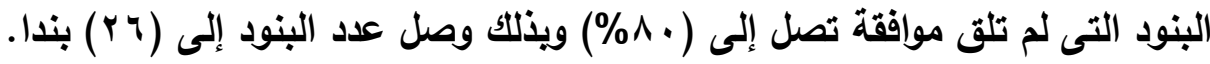
وصف العينة الاستطلاعية جدول (r) يوضح متوسط العمر للعينة الاستطلاعية للمدمنين والأسوياء

\begin{tabular}{|c|c|c|c|c|}
\hline \multicolumn{2}{|c|}{ الأسوياء ن= • r } & \multicolumn{2}{|c|}{ المدمنون ن= · r } & \multirow{2}{*}{ لمتغيرات } \\
\hline المعياري & المتوسط & الالمعياري & المتوسط & \\
\hline 0.0 & rq.Ar & $0 . V$ & $r V . r \Lambda$ & العمر \\
\hline
\end{tabular}


الفروق في السلوك التوكيدي بين المعتمدين وغير المعتمدين علي المواد النفسية.

جدول (r) يوضح تكرارات ونسب الحالة الاجتماعية

للعينة الاسنطلاعية للمدمنين والأسوياء

\begin{tabular}{|c|c|c|c|c|}
\hline \multicolumn{2}{|c|}{ الأسوياء ن=. r } & \multicolumn{2}{|c|}{ المدمنون ن= · r } & \multirow{2}{*}{ الحالة الاجتماعية } \\
\hline النسب & التكرارات & النسب & التكرارات & \\
\hline r..V & 11 & $\vee \neg . \vee$ & r & أعزب \\
\hline \multirow[t]{2}{*}{ r.r. } & 19 & r. & 7 & متزوج \\
\hline & & r. & 1 & مطلق \\
\hline
\end{tabular}

الثبات والصدة

قمنا بعمل الثبات والصدق على عينة من المدمنين قوامها ( • (r) مدمن وعلى عينة من الأسوياء مكونة من(·r) شخص سوي وجدول رقم (1)، (r) يوضح المتغيرات الايموجرافية للعينة، وستُعرض نتائج الثبات والصدق لكل عينة منفردة كما يلي:

\section{إجراءات الثبات والصدق للمقياس :}

\section{أولًا : إجراءات الاتساق اللداخلي}

حُسب الاتساق الاخاخي لمقياس السلوك التوكياي من خلال حساب ارتباط البند

بالارجة الكلية لدى كل من عينة المدمنين وعينة الأسوياء كما يلي: جدول (؛ ) يوضح ارتباط البند بالدرجة الكلية لمقياس السلوك التوكيدي

\begin{tabular}{|c|c|c|}
\hline عينة الأسوياء (· · ) & عينة المدمنين (· · ) & العبارة \\
\hline.$r \vee q$ & .17. & .1 \\
\hline$\cdot r \cdot r$ & $\cdot r \cdot r$ &.$r$ \\
\hline$\because 91$ & $\cdot r \cdot r$ &.$r$ \\
\hline$\because r \vee \wedge$ & .91 & . \\
\hline$\cdot . \leqslant \leqslant 7$ & .119 & 0 \\
\hline
\end{tabular}


الفروق في السلوك التوكيدي بين المعتمدين وغير المعتمدين علي المواد النفسية.

\begin{tabular}{|c|c|c|}
\hline $.11 \cdot-$ & ع سM. & .7 \\
\hline$. \bullet \leq r$ & $\because 01$ & 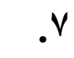 \\
\hline. $.17 \varepsilon$ & T. T. &.$\wedge$ \\
\hline.$r \varepsilon r$ & $\because Y 17$ & .9 \\
\hline$\cdot r r v$ & $\because r \varepsilon q$ & .1 \\
\hline$\because 1 \Lambda_{-}$ & $\because 1 r \cdot$ & .11 \\
\hline . & $\because 0$ & $.1 r$ \\
\hline$\because r \leq 7$ & $\because \varepsilon \varepsilon 0$ & $.1 \%$ \\
\hline$\because \varepsilon r q$ & $\because \mid Y_{1}$ & $.1 \varepsilon$ \\
\hline \multicolumn{3}{|c|}{ تابع :جدول (ع) يوضح ارتباط البند بالدرجة الكلية لمقياس السلوك التوكيدي } \\
\hline$\cdot r$ & 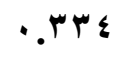 & .10 \\
\hline.$r V 0$ & $\because \leqslant \leqslant 0$ & .17 \\
\hline $.110_{-}$ & rצr. & .18 \\
\hline •r^r & •r. r & .11 \\
\hline$\cdot . \leqslant \wedge \leqslant$ & $\because 7 \cdot v$ & .19 \\
\hline$\because \cdots 9$ & .rpq &.$r$. \\
\hline$\bullet r \cdot \Lambda$ & qrr. &.$Y^{\prime}$ \\
\hline. .187 & $.1 \leq r$ &.$r Y$ \\
\hline • & .171 &.$r r$ \\
\hline $.7 \cdot 7$ & ו ו &.$Y \varepsilon$ \\
\hline.$\varepsilon V r$ & $.09 V$ &. ro \\
\hline $.0 \Lambda$. & qr r & צY \\
\hline
\end{tabular}




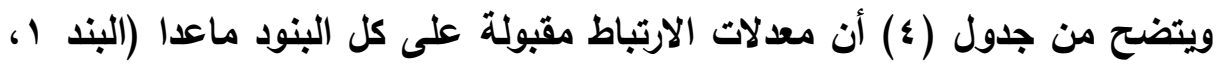

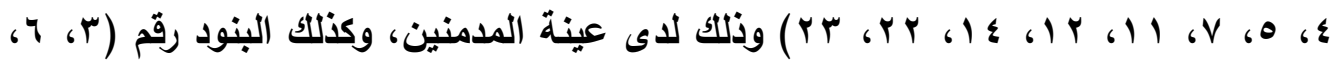



حُذفت البنود ذات الارتباطات المنخفضة وحُسبت الارتباطات مرة أخرى بعد الحذف، الحوباء والجدول رقم (0) يوضح الارتباطات بعد الحذف الاربط جدول (•) يوضح ارتباط البند بالدرجة الكلية لمقياس السلوك التوكياي بعد حذف البنود منخفضة الارتباط

\begin{tabular}{|c|c|c|}
\hline عينة الأسوياء (··) & عينة المدمنين (· • (r) & العبارة \\
\hline$\cdot r \leqslant V$ & $\because 1 \wedge$. & $r$ \\
\hline 政 & $\cdot r \leq \Lambda$ & 0 \\
\hline ט & & 9 \\
\hline$\cdot . r \vee q$ & . & 1. \\
\hline.$r \Delta 0$ & $\cdot . \leqslant \leqslant \mu$ & ir \\
\hline $.00 \mathrm{~V}$ & $\because \leqslant 00$ & 10 \\
\hline$\cdot r r q$ & $.0 Y 1$ & 17 \\
\hline..$\leqslant \leq \leqslant$ & $.0 Y_{1}$ & 11 \\
\hline.$r 90$ & $\cdot r q \leq$ & 19 \\
\hline $.1 r 0$ & $\because r \otimes \Lambda$ & Y \\
\hline$\because \leqslant 9 V$ & צחים & $r \varepsilon$ \\
\hline$\because r q V$ & $\because \leqslant r \leqslant$ & ro \\
\hline .091 & $\cdot . \leqslant \leqslant V$ & rq \\
\hline
\end{tabular}

ويتضح من الجدول السابق ارتفاع ارتباط بنود مقياس السلوك التوكيدي بالدرجة الكلية للمقياس بعد حذف البنود فأصبحت بنود المقياس (r I) بند ولديها جميعًا ارتباطات 


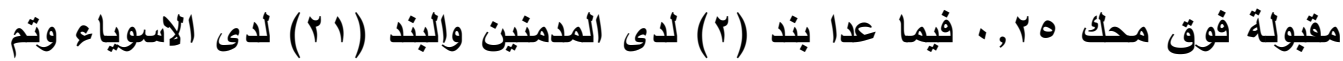
الابقاء عليهم لتماسك المقياس.

ثانيًا إجراءات الثبات:

تُحقق من ثبات المقياس لاى عينة المدمنين والأسوياء باستخدام معامل ألفا كرونباخ

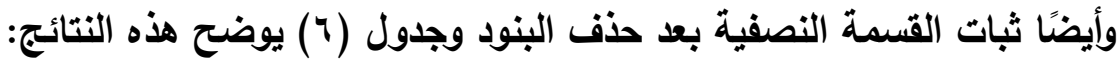

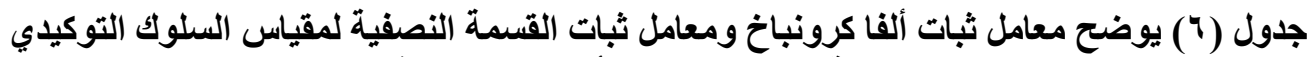

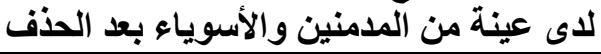

\begin{tabular}{|c|c|c|c|c|}
\hline \multicolumn{2}{|c|}{ عينة الأسوياء } & \multicolumn{2}{|c|}{ عينـة المدمنين } & \multirow{2}{*}{ المقياس } \\
\hline القسمة النصفية & معامل ألفا & القسمة النصفية & معامل ألفا & \\
\hline$\because \leqslant \wedge \theta$ &. .579 & $\because \leqslant 0 q$ & $\because \leq 7 \leq$ & مقياس السوكلوك \\
\hline
\end{tabular}

ويتضح من الجدول السابق أن معامل ألفا كرونباخ ومعامل القسمة النصفية متوسط



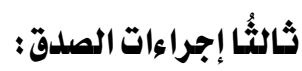

حُبِبَ صدق المجموعات المحكية وذلك عن طريق حساب الفروق بين مجموعة المدمنين ومجموعة الأسوياء باختبار (ت)، والجدول التالي يوضح نتائج صدق المجموعات جدول (V) يوضح الفروق بين مجموعة المدمنين ومجموعة الأسوياء

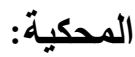
لحساب صدق المجموعات المحكية بعد الحذف ودين المدين

\begin{tabular}{|c|c|c|c|c|c|}
\hline \multirow[b]{2}{*}{ قيمة ت } & \multicolumn{2}{|c|}{ عينة الأسوياء } & \multicolumn{2}{|c|}{ عينة المدمنين } & \multirow[b]{2}{*}{ المقياس } \\
\hline & الانحراف & المتوسط & الانحراف & المتوسط & \\
\hline $.1 \leq \cdot 7$ & ૫. & $\Lambda .9 r$ & Y.\& & 9.49 & مقياس التوكيدي \\
\hline
\end{tabular}

ويتضح من جدول (آ) عدم وجود فروق بين عينة المدمنين وعينة الأسوياء مما يعني أن مقياس السلوك التوكيدي غير مميز بين المعتمدين وغير المعتمدين. الأساليب الإحصائية : الئي 1- الإحصاءات الوصفية للمتفيرات متمثلة في المتوسطات والانحراقات المعيارية. r - حساب الدلالة الإحصائية للفروق بين المتوسطات باستخدام اختبار (ت) . 




توجد فروق دالة إحصائيًابين المعتمدين وغير المعتمدين على المواد النفسية فى السلوك التوكيدي وللتحقق من هذا الفرض استخدم اختبار (ت) للفروق بين المعتمدين وغير

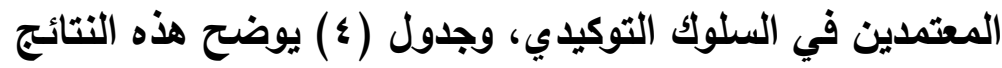



\begin{tabular}{|c|c|c|c|c|c|}
\hline \multirow[b]{2}{*}{ ت } & \multicolumn{2}{|c|}{ غير المعتمدين } & \multicolumn{2}{|c|}{ المعتمدين } & \multirow[b]{2}{*}{ المتغير } \\
\hline & المعياري & المتوسط & المعياري & المتوسط & \\
\hline $1 . \leqslant .0$ & †. 1 & 1.9 & T.乏 & $9 . \%$ & التوكليلوي \\
\hline
\end{tabular}

ويتضح من الجدول السابق عدم تحقق هذا الفرض؛ حيث أثثارت النتائج إلى في

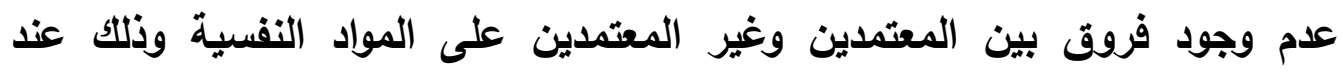
مستوى معنوية ه.,...

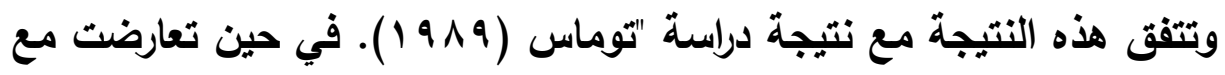

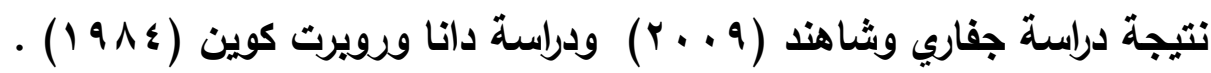

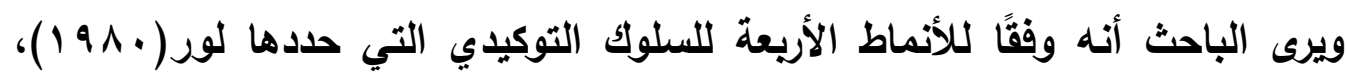
وهي:

1 - التوكيدية الاجتماعية: وتعني قدرة الفرد على بدء ومواصلة وإنهاء التفاعلات الاجتماعية بيسر وسهولة في مواقف العلاقات الثخصية.

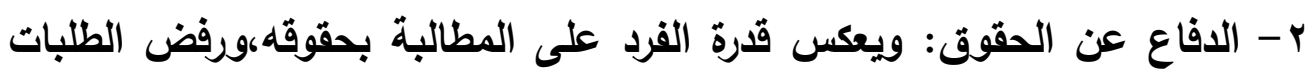


r- التوجيهية: وتعني قدرة الفرد على القيادة والتوجيه والتأثيرفي الآخرين.

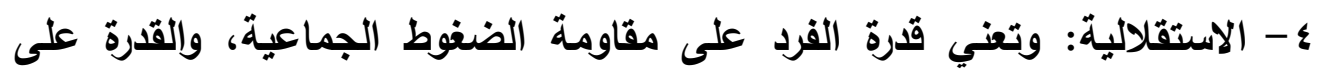

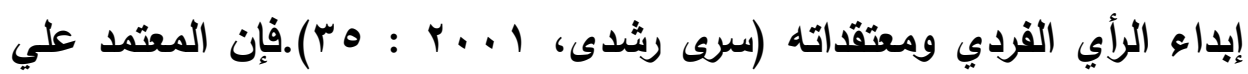
المواد النفسية يكتسب هذه السلوكيات والأنماط الأربعة حتي وإن كانت هذه 
الأنماط أو السلوكيات لا يقوم بها من قبل إدمانه، فإدمان الفرد يفرض عليه أن

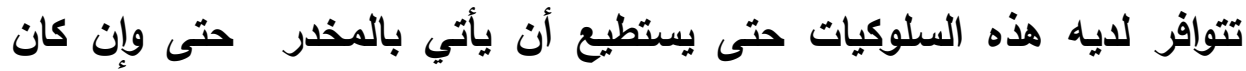
يستخدمها في ظل إدمانه بالثكل العدواني فإنه عندما يبقى في المستثفى لفترة فإنه يبدأ يظهز هذه السلوكيات بالثكل السليم إلى حد ما، وذلك عندما يقوم الفريق العلاجي الخاص به بلقت نظره إليها وطلب تعديل هذه السلوكيات. ويرى الباحث أن مريض الإدمان في المقابلات الأولية معله، وعند أخذ تاريخ الحالة، فإنه غالبًا ما يكون هناك قاسم مشترك بينهم فيما يخص سماتهم الثخصية بخصوص أنهم بصورة ما كانوا يفتقدون القدرة على توكيد الذات، والتعامل مع المشاعر، والملاحظ أنهم دائما ومن خلال جلسات العلاج الجمعي، وتحديدًا تلك الجلسات التى يُناقثون فيها بخصوص مكاسب وخسائر اعتمادهم على المواد النفسية، فإنهم غالبًا ما يقرون بأن أكبر مكاسبهم من المخدر هي، متعة المخدر، تسكين المشاعر السلبية، مثل القلق والخوف، وأن المخدر يعطيهم القدرة على التعامل

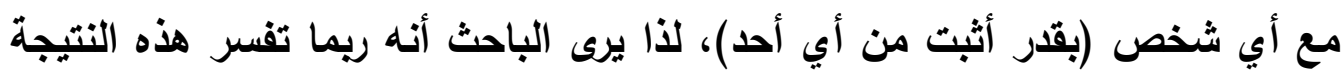
في ظل الفترة التي قضاها المرضى في عالم الإدمان والتي رفعت بطبيعة حالهم من

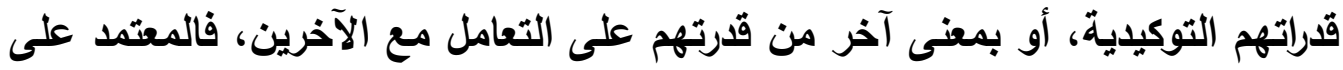

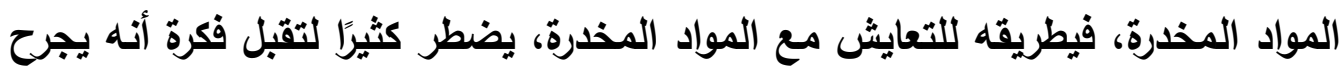
ويهين ويكنب ويسيء للآخرين، ومن ثم مع استمرارية تعاطيه يصل إلى ما يصفون به أنفسه فى الجلسات الفردية وجلسات العلاج الجمعي (المخدر بيخليك بجع غصبًا

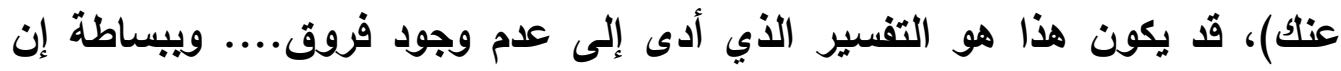

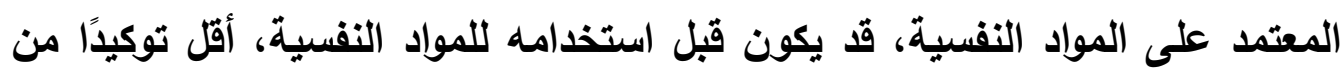
غير المعتمدين، ولكنه مع طريق الإدمان، ترتفع لديه مهارة التعبير عن الرفض ومخالفة الآخرين، وهو ما قد يؤدى إلى ارتفاع نتيجته على التقييم النفسى لتوكيد 


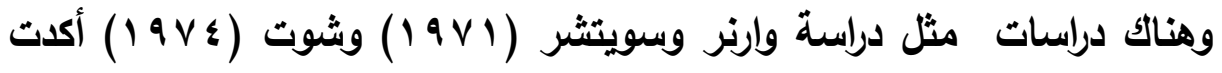

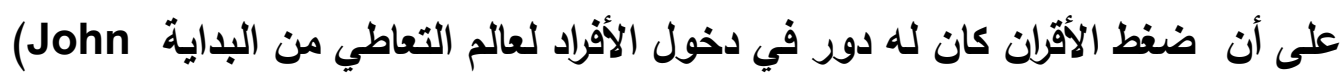

J. Horan, 1975:1)

وفي دراسة جون (9vo) (197)، التي هدفت إلى بحث العلاقة بين نمط التعاطي

ومقار التوكيدية، وقارن المجموعة بين أفراد لم يستخدموا المواد المخدرة أبدًا، أفراد استخدموا مواد مخدرة ومستمريين في تعاطيها، وأفراد استخذموا مواد مخدرة وأقلعوا عنها، وكانت المجموعة الأعلى توكيدية هي التي استخدمت المخدرات وأقلعت عنها.


من الـ "المجاراة الاجتماعية"، والاستجابة لضغوط الأقران بخصوص التعاطي، وتتثق

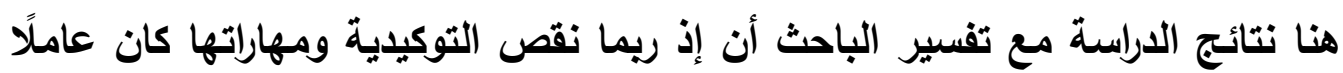

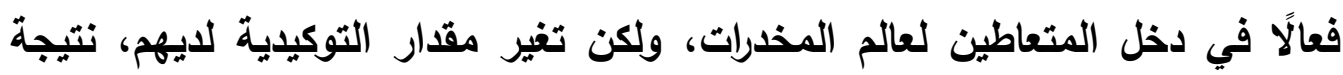



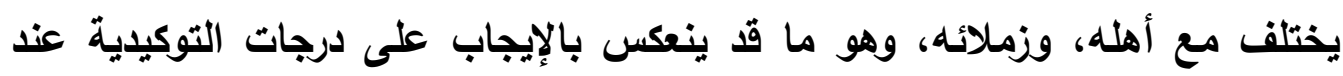

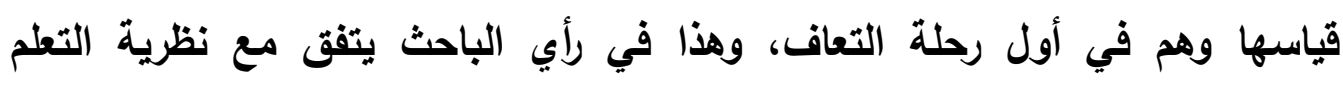

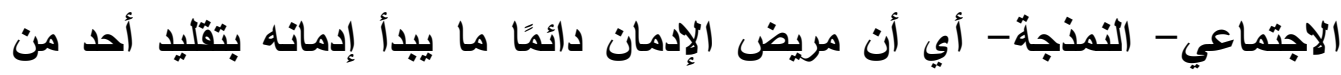

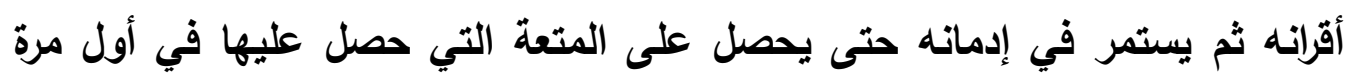

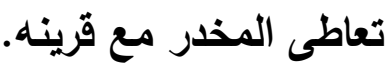




\section{قائمة المراجع}

\section{أولاً: المراجع العربية:}

- البحث القومي للإدمان (10 • ب). معدلات استعمال وإدمان المخدرات والكحوليات، التقرير المجمع لمراحل البحث القومي للإدمان، جمهورية مصر العربية، وحدة الأبحاث، الأمانة العامة للصحة النفسية.

- - داليا الجيزاوي (7 (†). مخاطر الإدمان فى مرحلتي الطفولة والمراهقة. مجلة الطقولة



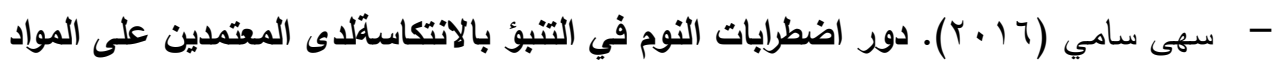

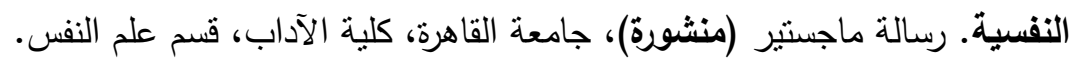

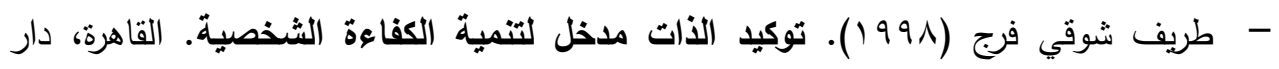
غريب للطباعة والنشر والتوزيع

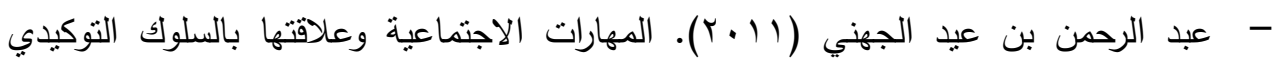



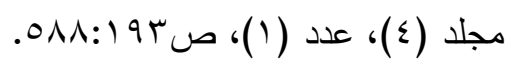

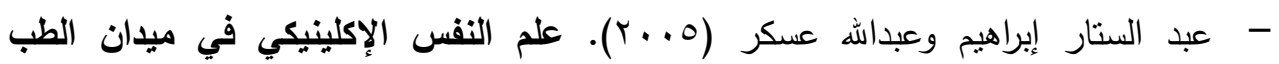
النفسى. القاهرة، مكتبة الأنجلو المصرية. - عبد الحميد عبد العظيم (9 . . ؟). الآثار النفسية لتعاطي وإدمان المخدرات. مركز الدراسات والبحوث قسم الندوات واللقاءات العلمية، جامعة نايف العربية للعلوم الأمنية.

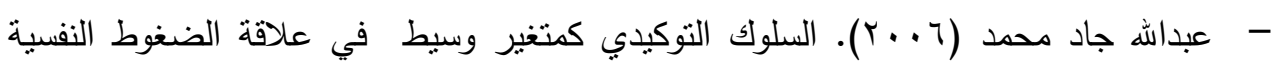

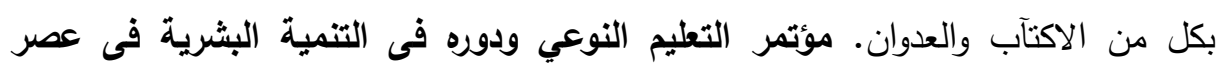

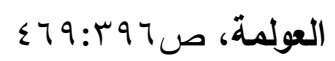

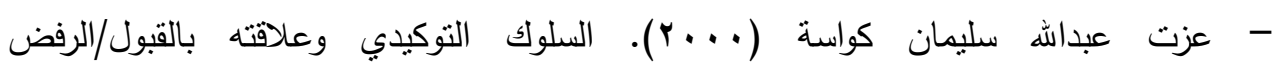

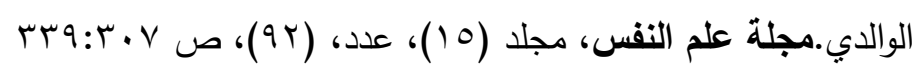

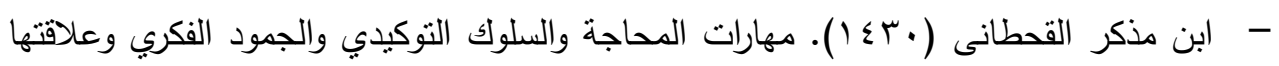
باتخاذ القرار لاى عينه من الطلاب الجامعيين بمدينة الرياض. رسالة دكتوراه (غير منشوراة)،




- كريمة خطاب سيد (9. (ب). العنف وعلاقته بتعاطي بعض المواد النفسية لدى طلاب

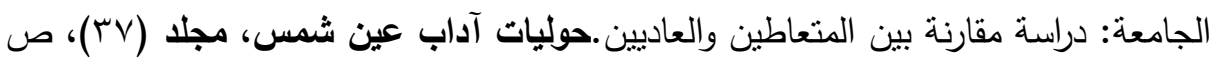
ro-1

- ماجدة حسين (1991) ميكولوجية المدمن العائد. رسالة ماجستير (غير منشورة)، جامعة عين شمس، كلية الآداب ، قسم علم النفس.

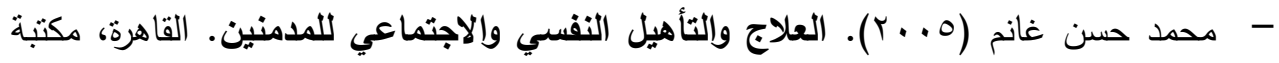
الأنجلو المصرية.

- - مصطفى سويف (1997 (1). المخدرات والمجتمع،نظرة تكاملية، الكويت،عالم المعرفة.

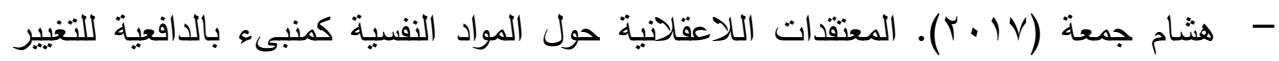

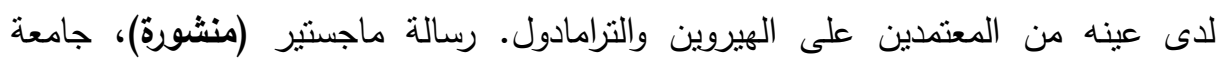

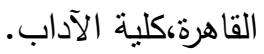
- مافي خليل (10 (10). فاعلية برنامج علاجي عقلاني انفعالي - سلوكي في خفض حدة اضطراب القلق وتحسين قوة الأنا لاى عينة من مدمني المخدرات في محافظة دمشق عادي رسالة دكتوراه (غير منشورة)، جامعة حماه، كلية الآداب والعلوم الإنسانية.

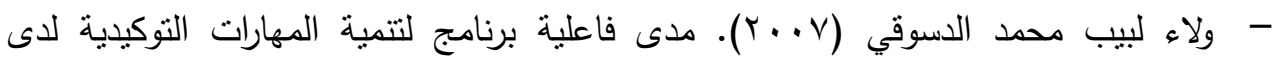

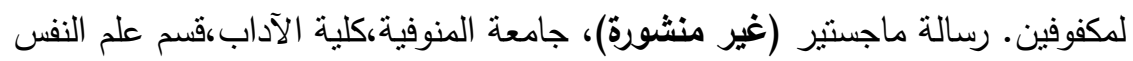

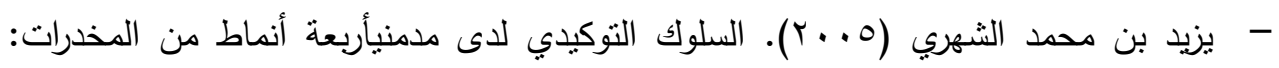

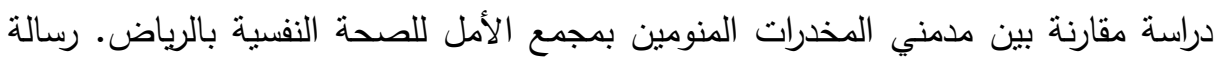
ماجستير (غير منشورة)، جامعة الرياض، قسم العلوم الاجتماعية.

\section{ثانياً: المراجع الاجنبية:}

- Adeina, D. (2007). The relation between emotional intelligence and substance addiction.United states, facility of California, ProQuest publishing.

- American Psychiatric Association. (2013). Diagnostic and Statistical manual of mental disorder (5thed, Text Revision ) . Washington, DC: APA.

- Bettinardi, K. \& Angres, D. (2013 ). Understanding the Disease of Addiction. Journal of Nursing Regulation, Volume 1/Issue 2,PP31-38

- Dianne, S.(1991). The EFFICACY OF assertiveness Training For Substance Abusers in a community Mental Health Center Intensive Outpatient Program. (unpublished Doctoral), Chicago School Of 
الفروق في السلوك التوكيدي بين المعتمدين وغير المعتمدين علي المواد النفسية.

Professional Psychology, Wayne state University, counseling. Retried from: ProQuest Publishing.

- Horan, J \& Damico, M \& Williams, J.(1975). Assertiveness And Patterns Of Drug Use-Apilot Study. Pennsylvania, J. Drug Education ,Volume 5, issue (3), 19:75.

- Jafari, M. \& Shahidi, S. (2009). Comparing locus of control, Assertiveness and General Health among Young Drug Dependent Patients in Iran. Iran Psychiatry, volume( 5), issue (4), PP46-51.

- Garner. E. (2012). Assertiveness, Recalim your Assertive Brighter, London, www.London.edu/mim/.

- Kelly, B. (2015). Assertiveness in professional women. (un published Master). Gonzaga univristy. Retried from :proquest Publishing.

- Kim, I. (2001). theeffects of assertiveness training on enhancing the social skills of adolescents with visual impairments. (unpublished Master). Peabody college Vanderbilt University. Retried from : proquest dissertation publishing.

- Nelson, E. (1982). Assertiveness Training Using Rehearsalandmolding with Male Alcoholics. (Unpublished doctor), Brigham Young University, Department of Psychology. Retried from: Dissertation ProQuest Publishing

- Steiner, C. \& Lucille, J. (1981). An Investigation of the Effectiveness Of Assertion Training As A Treatment Modality With Drug Addicts. (Unpublished master). University of Miami. Retried from: Proquest Dissertations Publishing.

- West, R. (2005). Theory of Addiction. London: Addiction Press Series.

- World Drug Report.(2015). United Nations Office on Drugs and Crime. UNODC, New York. 